\title{
BIOPHYSICS
}

Vol. 4, pp. 29-32 (2008)

doi: $10.2142 /$ biophysics.4.29

\section{Pressure acceleration of proteolysis: A general mechanism}

\author{
Kazuyuki Akasaka ${ }^{1}$, Harumi Nagahata ${ }^{2}$, Akihiro Maeno ${ }^{2}$ and Ken Sasaki ${ }^{1}$ \\ ${ }^{1}$ High Pressure Protein Research Center, Institute of Advanced Technology, Kinki University, 930 Nishimitani, Kinokawa 649-6493, Japan \\ ${ }^{2}$ School of Biology-Oriented Science and Technology, Kinki University, 930 Nishimitani, Kinokawa 649-6493, Japan
}

Received 13 September, 2008; accepted 1 November, 2008

\begin{abstract}
Remarkable acceleration of enzymatic proteolysis by pressure at kbar range is reported with ubiquitin as substrate and $\alpha$-chymotrypsin as enzyme. The acceleration is interpreted in terms of the shift of conformational equilibrium in ubiquitin from the non-degradable folded conformer to the enzyme-degradable unfolded conformer by pressure because of the lower volume of the latter, while the enzymatic activity of $\alpha$-chymotrypsin is still largely retained. This mechanism is considered generally applicable to most globular proteins and the method of pressure-accelerated proteolysis will have an enormous potential utility in systems wherever efficient removal of proteins is needed.
\end{abstract}

Key words: pressure-enhanced proteolysis, shift of conformational equilibrium, unfolded conformer, ubiquitin, $\alpha$-chymotrypsin

Pressure-induced acceleration of proteolysis by $\alpha$-chymotrypsin has been reported ${ }^{1,2}$ previously with artificial compound or peptide as substrate ${ }^{1,2}$. The acceleration of the reaction is usually analyzed in terms of the activation of the enzyme activity itself by pressure, namely in terms of the activation volume in the reaction rate theory ${ }^{3}$, which turned out to be negative ${ }^{2}$. In the present work, we have observed a dramatic increase in the proteolysis reaction by $\alpha$-chymotrypsin under pressure when the substrate is not an artificial

Corresponding author: Kazuyuki Akasaka, High Pressure Protein Research Center, Institute fo Advanced Technology, Kinki University, 930 Nishimitani, Kinokawa 649-6493, Japan.

e-mail: akasaka@waka.kindai.ac.jp compound or peptide, but a globular protein, ubiquitin. Ubiquitin is a small protein consisting of 76 amino acids with a molecular mass of about $8.5 \mathrm{kDa}$ and its basic folded structure is well established in crystal $^{4}$ and in solution ${ }^{5,6}$. Ubiquitin occurs in all eukaryotic cells and works as a posttranslational tag for signaling a protein's hydrolytic destruction. Here we choose ubiquitin as a first target of study on the mechanism of pressure-enhanced hydrolysis, because it is known to be a protein which strongly resists to proteolysis by $\alpha$-chymotrypsin under normal conditions, while less stable proteins with similar folds readily receive proteolysis ${ }^{7,8}$.

In general, as long as a globular protein remained strictly in its folded state with little fluctuation in the structure, it would not be hydrolyzed by a proteolytic enzyme, because the rigidity of the folded structure of the substrate protein would prohibit its binding onto the catalytic crevice of the proteolytic enzyme in a favorable conformation for the catalytic reaction to proceed ${ }^{9}$. Often, however, when the folded conformation of the substrate protein becomes unstable, for example by a site-directed mutation, the unfolded conformation is increased in equilibrium, and then it becomes prone to enzymatic proteolysis ${ }^{10}$. This is because the "floppy" polypeptide chain of the unfolded conformation would enable favorable binding of the substrate protein onto the catalytic side of the peoteolytic enzyme'.

In this context, our previous high pressure NMR studies disclosed that, although ubiquitin is an exceptionally stable protein thermodynamically, it exists in dynamic equilibrium among various conformers including basic folded conformer $\left(\mathrm{N}_{1}\right)$, an open conformer $\left(\mathrm{N}_{2}\right)$ and a locally disordered conformer (I) and even the fully unfolded conformer (U) even under closely physiological conditions ${ }^{11-13}$. Since the equi- 
librium populations of the unfolded conformer is so low under normal conditions (estimated population $\sim 0.001 \%$ at at $\mathrm{pH} 4.5$ and $\left.0^{\circ} \mathrm{C}\right)^{11}$ that ubiquitin resists strongly against proteolysis by $\alpha$-chymotrypsin ${ }^{7,8}$. However, we found that the populations of $\mathrm{I}$ and $\mathrm{U}$ conformers are dramatically increased by pressure at kbar range $\mathrm{e}^{11-13}$. Based on this information, a new experiment is designed here to use hydrostatic pressure for enhancing the proteolysis reaction of ubiquitin by dramatically increasing the population of the proteolysis-prone unfolded conformer.

\section{Materials and methods}

Ubiquitin and $\alpha$-chymotrypsin from bovine pancreas Type II were obtained from Sigma Chem. Co. and used without further purification. For enzymatic hydrolysis of ubiquitin, solutions containing ubiquitin $(31 \mu \mathrm{M})$ and $\alpha$ chymotrypsin $(3 \mu \mathrm{M})$ in $10 \mathrm{mM}$ Tris- $\mathrm{HCl}$ buffer $(\mathrm{pH} 7.0)$ were subjected to different pressures up to $4 \mathrm{kbar}$ for different time intervals up to $60 \mathrm{~min}$ in a high pressure vessel PCI-400 connected to a hand-pump TP-500 (Teramecs, Kyoto). The temperature of the sample solution was maintained with a water-jacketed temperature control unit at $37^{\circ} \mathrm{C}$. Pressure was increased to a desired value within $\sim 5 \mathrm{~min}$, and after an appropriate time interval at that pressure was released to 1 bar within $\sim 1 \mathrm{~min}$. Then the reaction products were analyzed on SDS-PAGE to examine the degradation of ubiquitin.

The conformational stability of $\alpha$-chymotrypsin $(3 \mu \mathrm{M}$ in $10 \mathrm{mM}$ Tris- $\mathrm{HCl}$ buffer, $\mathrm{pH} 7.0$ ) against pressure was independently measured at $37^{\circ} \mathrm{C}$ with $\operatorname{Trp}$ fluorescence as monitor in the pressure range between 1 bar and $4 \mathrm{kbar}$ on a fluorescence spectrophotometer (Shimadzu RF-5300PC) equipped with a high pressure chamber (PCI-400) and a hand-pump (TP-500, both from Teramecs, Kyoto).

\section{Results}

Figure 1 shows the result of SDS-PAGE analysis of ubiquitin subjected to digestion with $\alpha$-chymotrypsin in solutions containing ubiquitin $(31 \mu \mathrm{M})$ and $\alpha$-chymotrypsin $(3 \mu \mathrm{M})$ in $10 \mathrm{mM}$ Tris- $\mathrm{HCl}$ buffer $(\mathrm{pH} 7.0)$ for $50 \mathrm{~min}$ at various pressures from 1 bar to 3500 bar at $37^{\circ} \mathrm{C}$. At 1 bar, no degradation products were detected (Fig. 1a). When we applied pressure, the situation dramatically changed. At 500 bar the band for intact ubiquitin started getting smaller and continued to decrease at 1000 and 1500 bar. At 2000 bar, the ubiquitin band nearly disappeared, showing that ubiquitin was almost degraded. The pressure enhancement of proteolysis of ubiqutin with $\alpha$-chymotrypsin is quite dramatic. The result also indicates that $\alpha$-chymotrypsin retains its catalytic activity at $2 \mathrm{kbar}$ or higher, meaning that its activity is not totally destroyed by this range of pressure.

As a convenient measure of stability of the native conformation of $\alpha$-chymotrypsin against pressure, we monitored

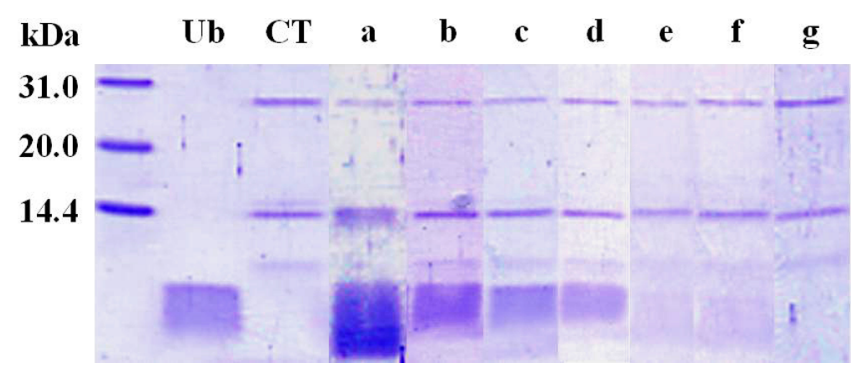

Figure 1 SDS-PAGE patterns for ubiquitin subjected to enzymatic hydrolysis with $\alpha$-chymotrypsin at $37^{\circ} \mathrm{C}$ for $50 \mathrm{~min}$ at following pressures. a. 1 bar, b. 500 bar, c. 1000 bar, d. 1500 bar, e. 2000 bar, f. 2500 bar, g. 3500 bar. The solution contained ubiquitin $(31 \mu \mathrm{M})$ and $\alpha$-chymotrypsin $(3 \mu \mathrm{M})$ in $10 \mathrm{mM}$ Tris- $\mathrm{HCl}$ buffer, $\mathrm{pH}$ 7.0. Lanes for ubiquitin alone and $\alpha$-chymotrypsin alone are also shown for comparison.

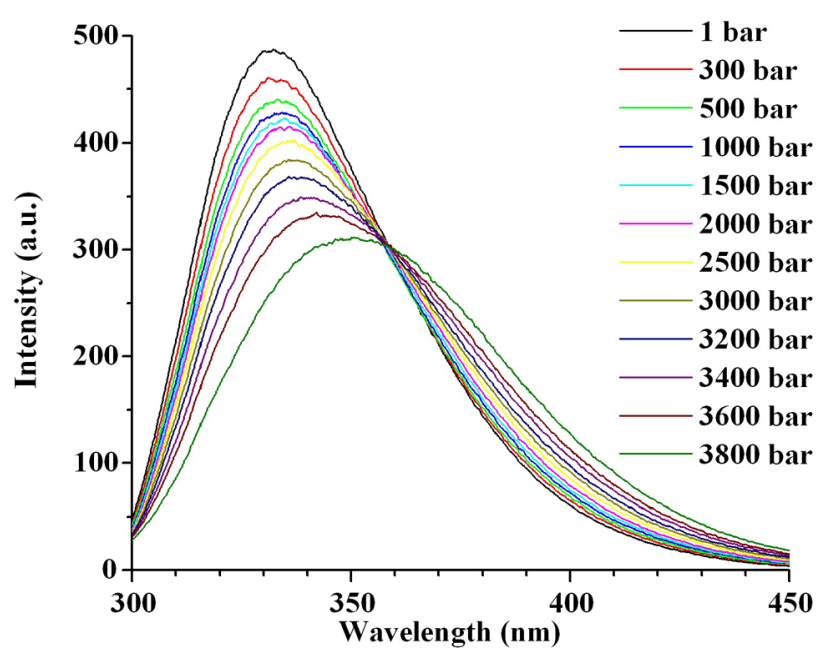

Figure 2 Fluorescence spectra of $\alpha$-chymotrypsin $(3 \mu \mathrm{M})$ in $10 \mathrm{mM}$ Tris- $\mathrm{HCl}$ buffer, $\mathrm{pH} 7.0$ at $37^{\circ} \mathrm{C}$, measured at various pressures from 1 bar up to 3800 bar. The maximum emission wavelength $\lambda_{\max }$ at $332.2 \mathrm{~nm}$ gradually shifts to red with increasing pressure, finally to $350.5 \mathrm{~nm}$ at $3.8 \mathrm{kbar}$.

its Trp fluorescence as a function of pressure in $10 \mathrm{mM}$ Tris- $\mathrm{HCl}$ buffer ( $\mathrm{pH} 7.0$ ) at $37^{\circ} \mathrm{C}$ (Fig. 2). The maximum emission wavelength $\left(\lambda_{\max }\right)$ was initially at $332.2 \mathrm{~nm}$, indicating that Trp residues are buried in the folded conformation of $\alpha$-chymotrypsin. It gradually increased with increasing pressure, but stayed within $332 \sim 336 \mathrm{~nm}$ below $3 \mathrm{kbar}$, which strongly suggests that the original native Trp environment is largely unchanged. Finally at $3.8 \mathrm{kbar}, \lambda_{\max }$ shifts to $350.5 \mathrm{~nm}$, indicating that at this pressure the protein is largely denatured. The above results strongly suggest that, under the present experimental condition for the proteolytic reaction under pressure, the native environment of $\alpha$-chymotrypsin is largely retained at least below $3 \mathrm{kbar}$ and therefore that its catalytic activity would be retained, if not at the same level as that at 1 bar. 


\section{General mechanism for pressure enhancement of proteolysis}

The enormous enhancement of proteolysis of ubiquitin by pressure cannot be explained by the increase in catalytic activity of the enzyme $\alpha$-chymotrypsin itself by pressure, which is reported to be several-fold in an experiment using artificial substrate ${ }^{2}$. Alternatively, the effect must be interpreted in terms of the conformational transition of the substrate ubiquitin from the proteolysis-resistive folded form into a proteolysis-prone unfolded form.

Because the disordered and/or unfolded conformers have lower partial molar volumes than the folded conformer $\mathrm{N}$ (Volume Theorem ${ }^{14}$ ), the populations of the former can be dramatically increased at high pressure ${ }^{14,15}$. Even at a moderate range of pressure (a few hundred bar to a few kbar) such that disordered and/or unfolded conformers may still remain undetected, their populations are increased dramatically by a few orders-of-magnitude from those at 1 bar. This is because the relative population of high-energy conformers (e.g., unfolded conformer $\mathrm{U}$ ) to that of the folded conformer $\mathrm{N}$ at pressure $\mathrm{P}$ is given by

$$
\mathrm{p}_{\mathrm{U}} / \mathrm{p}_{\mathrm{N}}=\exp \left\{-\left(\Delta \mathrm{G}_{\mathrm{U}-\mathrm{N}}{ }^{0}+\mathrm{P} \Delta \mathrm{V}_{\mathrm{U}-\mathrm{N}}\right) / \mathrm{RT}\right\}
$$

where $\Delta \mathrm{G}_{\mathrm{U}-\mathrm{N}}{ }^{0}$ is the Gibbs energy of conformer $\mathrm{U}$ relative to $\mathrm{N}$ at 1 bar and $\Delta \mathrm{V}_{\mathrm{U}-\mathrm{N}}$ is the change in partial molar volume of conformer $\mathrm{U}$ relative to $\mathrm{N}$. In principle, $\Delta \mathrm{V}_{\mathrm{U}-\mathrm{N}}$ can change with pressure, but here we may assume that $\Delta \mathrm{V}_{\mathrm{U}-\mathrm{N}}$ is an average value of the partial molar volume change over the range of pressure of interest and in fact may be assumed to be close to $\Delta \mathrm{V}_{\mathrm{U}-\mathrm{N}}{ }^{0}$, as the dependence of $\Delta \mathrm{V}_{\mathrm{U}-\mathrm{N}}$ against pressure has seldom been carried out. Thus the population of conformer $\mathrm{U}$ at pressure $\mathrm{P}$ relative to that at 1 bar is given by the ratio of $\exp \left\{-\left(\Delta \mathrm{G}_{\mathrm{U}-\mathrm{N}}{ }^{0}+\mathrm{P} \Delta \mathrm{V}_{\mathrm{U}-\mathrm{N}}\right) / \mathrm{RT}\right\}$ to $\exp \left\{-\Delta \mathrm{G}_{\mathrm{U}-\mathrm{N}}{ }^{0} / \mathrm{RT}\right\}$, namely by $\exp \left(-\mathrm{P} \Delta \mathrm{V}_{\mathrm{U}-\mathrm{N}} / \mathrm{RT}\right)$, which indicates that the population of the rare (unfolded) conformer increases exponentially with increasing pressure.

For ubiquitin at $\mathrm{pH} 4.5$ and $0^{\circ} \mathrm{C}$, the stability at 1 bar $\left(\Delta \mathrm{G}_{\mathrm{U}-\mathrm{N}}{ }^{0}\right)$ was determined previously to be $31.3+/-4.7 \mathrm{~kJ} / \mathrm{mol}$, while the change in partial molar volume $\Delta \mathrm{V}_{\mathrm{U}-\mathrm{N}}$ to be -85 $\mathrm{ml} / \mathrm{mol}$ at $\mathrm{pH} 4.5$ and $0^{\circ} \mathrm{C}^{11}$. With an assumption of constant $\Delta \mathrm{V}_{\mathrm{U}-\mathrm{N}}$ over the range of pressure in eq. 1 , we estimate that at 1 bar the population of $U$ is less than $0.001 \%$, which will be increased by an order of magnitude to $\sim 0.01 \%$ at $0.7 \mathrm{kbar}$, to $\sim 0.1 \%$ at $1.4 \mathrm{kbar}$, and to $>1 \%$ at $>2.0 \mathrm{kbar}$. Our proteolysis reaction had to be carried out at different conditions $(\mathrm{pH} 7.0$, $37^{\circ} \mathrm{C}$ ) and therefore the estimate of population $U$ could be somewhat different from the above. Nevertheless, the above estimate demonstrates the fact that pressure within a few kbar range increases the population of the proteolysis-prone unfolded conformer dramatically, while a proteolytic enzyme, e.g., $\alpha$-chymotrypsin, is still active (cf. Fig. 2). Thus, we propose a simple mechanism for the pressure enhancement of enzymatic proteolysis for a globular protein as shown schematically in Figure 3. Here the essence is that pressure shifts the conformational equilibrium between $\mathrm{N}$ and $\mathrm{U}$ in

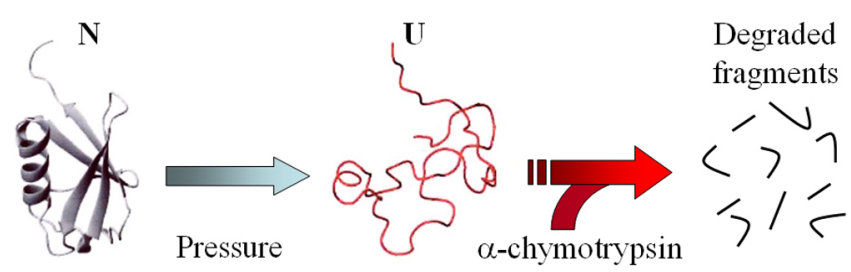

Figure 3 General mechanism for pressure enhancement of enzymatic proteolysis of a globular protein. Pressure shifts the population from $\mathrm{N}$ to $\mathrm{U}$ according to eq. 1 and $\mathrm{U}$ is subsequently degraded by an proteolytic enzyme, e.g. $\alpha$-chymotrypsin under pressure.

favor of $U$ according to eq. 1, which is subsequently degraded by $\alpha$-chymotrypsin under pressure.

\section{Concluding remark}

As the volume change from $\mathrm{N}$ to $\mathrm{U}\left(\Delta \mathrm{V}_{\mathrm{U}-\mathrm{N}}\right)$ is normally negative for globular proteins at physiological or lower temperatures, exponential increase in population of the unfolded conformer $\mathrm{U}$ with pressure is generally expected. At a relatively low pressure ( $<$ a few kbar) where proteolytic enzymes are still active, enormous increase in the rate of proteolysis by pressure is generally anticipated. Thus the mechanism depicted in Figure 3 should be widely applicable to globular protein/proteolytic enzyme systems besides the ubiquitin/ $\alpha$ chymotrypsin system. For example, a recent report ${ }^{16}$ on the enhanced trypsin-digestion of bovine serum albumin using pressure cycling technology will be perfectly explained by this mechanism. The use of pressure for increasing the proteolysis-prone form of the protein is simple and logical, because one may design the experiment apriori based on the known values of $\Delta \mathrm{G}_{\mathrm{U}-\mathrm{N}}{ }^{0}$ and $\Delta \mathrm{V}_{\mathrm{U}-\mathrm{N}}$ and the knowledge on the stability of the proteolytic enzyme against pressure. Pressure enhancement of proteolysis will have enormous practical utility in systems in which efficient removal of proteins are desired.

\section{Acknowledgement}

This work was carried out under the auspice of the Academic Frontier Program from the Ministry of Education, Culture, Sports, Science and Technology of Japan.

\section{References}

1. Taniguchi, Y. \& Suzuki, K. Pressure inactivation of alphachymotrypsin. J. Phys. Chem. 87, 5185-5193 (1983).

2. Mozhaev, V. V., Lange, R., Kudryashova, E. V. \& Balny, C. Application of high hydrostatic pressure for increasing activity and stability of enzymes. Biotechnol. Bioeng. 52, 320-331 (1996).

3. Morild, E. The theory of pressure effects on enzymes. $A d v$. Prot. Chem. 34, 93-166 (1981).

4. Vijay-Kumar, S., Bugg, C.E. \& Cook, W. J. Structure of ubiquitin refined at $1.8 \AA$ resolution. J. Mol. Biol. 194, 531544 (1987).

5. Weber, P. L., Brown, S. C. \& Mueller, L. Sequential ${ }^{1}$ H NMR 
assignments and secondary structure identification of human ubiquitin. Biochemistry 26, 7282-7290 (1987).

6. Cornilescu, G., Marquardt, J.L., Ottiger, M. \& Bax, A Validation of protein structure from anisotoropic carbonyl chemical shifts in dilute liquid crystalline phase. J. Am. Chem. Soc. 120, 6836-6837 (1998).

7. Kitahara, R., Yamaguchi, Y., Sakata, E., Kasuya, T., Tanaka, T., Kato, K., Yokoyama, S. \& Akasaka, K. Evolutionally conserved intermediates between ubiquitin and NEDD8. J. Mol. Biol. 363, 395-404 (2006).

8. Kitahara, R., Zhao, C., Saito, K., Koshiba, S., Ioune, M., Kigawa, T., Yokoyama, S. \& Akasaka, K. Basic folded and low-populated locally disordered conformers of SUMO-2 characterized by NMR spectroscopy at varying pressures. Biochemistry 47, 30-39 (2008).

9. Hiromi, K., Akasaka, K., Tonomura, B., Mitsui, Y. \& Murao, S. Protein Protease Inhibitor-The Case of Streptomyces Subtilisin Inhibitor (SSI). (Elsevier Science Publishers, 1985).

10. Tamura, A., Kanaori, K., Kojima, S., Kumagai, I., Miura, K. \& Akasaka, K. Mechanisms of temporary inhibition in Streptomyces subtilisin inhibitor induced by an amino acid substitution, tryptophan 86 replaced by histidine. Biochem- istry 30, 5275-5286 (1991).

11. Kitahara, R. \& Akasaka, K. Close identity of a pressurestabilized intermediate with a kinetic intermediate in protein folding. Proc. Nat. Acad. Sci. USA 100, 3167-3172 (2003).

12. Kitahara, R., Yokoyama, S. \& Akasaka, K. NMR snapshots of a fluctuating protein structure. Ubiquitin at $30 \mathrm{bar}-3 \mathrm{kbar}$. J. Mol. Biol. 347, 277-285 (2005).

13. Kitahara, R., Okuno, A., Kato, M., Taniguchi, Y., Yokoyama, S. \& Akasaka, K. Cold denaturation of ubiquitin at high pressure. Magn. Reson. Chem. 44, S108-S113 (2006).

14. Akasaka, K. Probing conformational fluctuation of proteins by pressure perturbation. Chem. Rev. 106, 1814-1835 (2006).

15. Kamatari, Y. O., Kitahara, R., Yamada, H., Yokoyama, S. \& Akasaka, K. High-pressure NMR spectroscopy for characterizing folding intermediates and denatured states of proteins. Methods 34, 133-143 (2004).

16. Lopez-Ferrer, D., Petritis, K., Hixson, K. K., Heibeck, T. H., Moore, R. J., Belov, M.E., Camp II, D. G. \& Smith, R. D. Application of pressurized solvents for ultrafast trypsin hydrolysis in proteomics: Proteomics on the fly. J. Proteome Res. 7, 3276-3281 (2008). 